\title{
Extraction of Monodisperse Palladium Nanoparticles from Dendrimer Templates
}

\author{
Joaquin C. Garcia-Martinez, Robert W. J. Scott, and Richard M. Crooks* \\ Department of Chemistry, Texas A\&M University, P.O. Box 30012, College Station, Texas 77842-3012
}

Received July 10, 2003; E-mail: crooks@tamu.edu

We report that size-monodisperse Pd nanoparticles can be extracted intact from dendrimer templates using $n$-alkanethiols. This is a significant discovery for several reasons. First, it demonstrates that nanometer-scale materials prepared within a molecular template can be removed, leaving both the replica and template undamaged. Second, it provides a straightforward approach for preparing highly monodisperse metallic and bimetallic monolayer-protected clusters (MPCs) $)^{1-3}$ without need for subsequent purification. Third, it demonstrates that multiple, fairly complex operations, including formation of covalent bonds, electron-transfer, molecular transport, heterogeneous self-assembly, and nanoparticle transport, can all be executed within the interior of a 4.5-nm dendrimer. These points are demonstrated here by templating the formation of $\sim 1.7-\mathrm{nm} \mathrm{Pd}$ nanoparticles within poly(amidoamine) (PAMAM) dendrimers, ${ }^{4-8}$ and then extracting the Pd into a toluene phase while leaving the dendrimer in the aqueous phase (Scheme 1).

Dendrimer-encapsulated nanoparticles (DENs) ${ }^{4-7}$ are prepared in a two-step process. First, metal ions are sequestered within the dendrimer, and then the ions are chemically reduced. Because the synthesis relies on a dendrimeric template, the resulting metal nanoparticle (the replica) can be quite monodisperse in size. Among the desirable characteristics of DENs are that they can be solubilized in nearly any solvent, ${ }^{4}$ they are catalytically active, ${ }^{6-8}$ the dendrimer itself can be used to lend functionality to the nanoparticle composite, ${ }^{7}$ and recently it has been shown that very small DENs can be highly luminescent. ${ }^{9}$ There have been two prior reports of ligand adsorption to Au DENs, in one case a thiol ${ }^{10}$ and in the other a disulfide, ${ }^{11}$ but there was no evidence for extraction of the nanoparticle in either case.

There are several other approaches for preparing metal nanoparticles in the $<2-\mathrm{nm}$ size range. For example, MPCs are commonly prepared by mixing a metal salt, a chemical reducing agent, and a surfactant ${ }^{2,12}$ (often an $n$-alkanethiol). The reductant initiates particle growth, which is eventually quenched by adsorption of the surfactant. MPCs can also be synthesized by postsynthesis ligand-exchange reactions starting with polymer-stabilized clusters. ${ }^{13}$ MPCs have many desirable attributes: they can be repeatedly isolated from and redissolved in common organic solvents without irreversible aggregation or decomposition, ${ }^{14}$ their surface can be functionalized with a vast range of modifiers, and they can be linked to polymers, biomolecules, and monolithic surfaces. ${ }^{1-3}$ Most reports of MPCs focus on $\mathrm{Au},{ }^{1-3}$ but Pd MPCs have also been reported in the literature with sizes ranging from 2.3 to $6.5 \mathrm{~nm} .{ }^{15-18}$ The approach we describe is fundamentally different from these methods, because nanoparticle formation relies on preloading a welldefined molecular template rather than on less easily controlled nucleation and growth phenomena. Consequently, the size and size distribution of the resulting MPCs can be tightly controlled without need for purification.

The first step for preparing MPCs using this template-based approach requires synthesis of Pd DENs. We prepared these using

\section{Scheme 1}

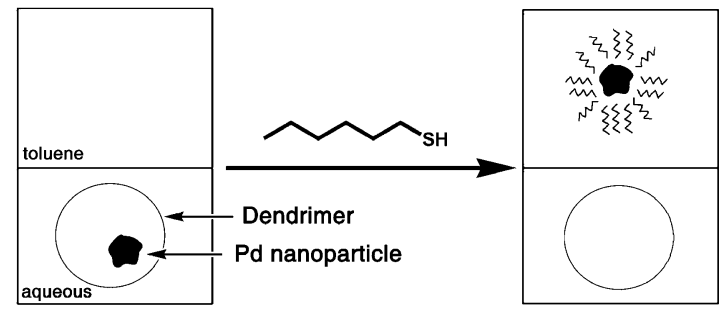

a slight variation of our previously published procedure. ${ }^{6,7}$ Specifically, $6.25 \mu \mathrm{M}$ fourth-generation, hydroxyl-terminated PAMAM dendrimers $(\mathrm{G} 4-\mathrm{OH})$ were mixed with $250 \mu \mathrm{M} \mathrm{Pd}\left(\mathrm{CH}_{3} \mathrm{COO}\right)_{2}$ in $10 \mathrm{~mL}$ of water to yield $\mathrm{G} 4-\mathrm{OH}\left(\mathrm{Pd}^{2+}\right)_{40}$. Next, metal ion reduction was carried out by mixing the $\mathrm{G} 4-\mathrm{OH}\left(\mathrm{Pd}^{2+}\right)_{40}$ solution with a 100fold excess of $\mathrm{NaBH}_{4}$ for 10 min to yield a brown $\mathrm{G} 4-\mathrm{OH}\left(\mathrm{Pd}_{40}\right)$ solution. In the second step, the Pd DENs are extracted from the dendrimer interior. This is accomplished by adding $10 \mathrm{~mL}$ of a $500 \mu \mathrm{M} n$-hexanethiol solution in toluene to the aqueous phase (final $\mathrm{Pd}$ atom:thiol ratio $=1: 2$ ). After shaking for $5 \mathrm{~min}$ the aqueous phase turned from brown to colorless, and the toluene phase turned from colorless to brown, indicating extraction of the nanoparticles from the dendrimer and their transport into the toluene phase (Supporting Information, Figure S1).

Figure 1 shows UV-vis absorption spectra for the aqueous G4$\mathrm{OH}\left(\mathrm{Pd}_{40}\right)$ phase prior to extraction (solid line), and the toluene (dashed line) and aqueous (dotted line) phases after extraction. Prior to extraction, the aqueous $\mathrm{G} 4-\mathrm{OH}\left(\mathrm{Pd}_{40}\right)$ solution displays one intense band at $200 \mathrm{~nm}$, corresponding to absorption by the dendrimer and $\mathrm{BH}_{4}{ }^{-}$. A monotonically increasing absorbance toward higher energy, which results from interband transitions of the encapsulated zerovalent Pd nanoparticles, is also observed. ${ }^{6}$ After extraction, the spectrum of the toluene phase is very similar to that of the aqueous phase before extraction in both form and intensity (the spectrum is cut off below $285 \mathrm{~nm}$ due to toluene absorption). The slight variation in intensity probably results from slight differences in nanoparticle concentration or solvent diffraction index. ${ }^{19}$

After extraction, the aqueous phase was dialyzed for $48 \mathrm{~h}$ to remove toluene and $\mathrm{BH}_{4}{ }^{-}$, and the resulting absorbance spectrum (dotted line, Figure 1) did not reveal the characteristic interband absorption signature of Pd DENs; only the peak corresponding to the G4-OH dendrimer is present (Supporting Information, Figure S2). FT-IR spectroscopy of both the toluene and aqueous phases after extraction showed that the dendrimer is only present in the aqueous phase (Supporting Information, Figures S3 and S4). This means that the dendrimer remains in the aqueous phase after extraction and thus could be recycled. This result can be contrasted with an earlier report, which showed that it was possible to extract both the dendrimer and the encapsulated nanoparticle into a toluene phase upon addition of an appropriate surfactant. ${ }^{20}$ 


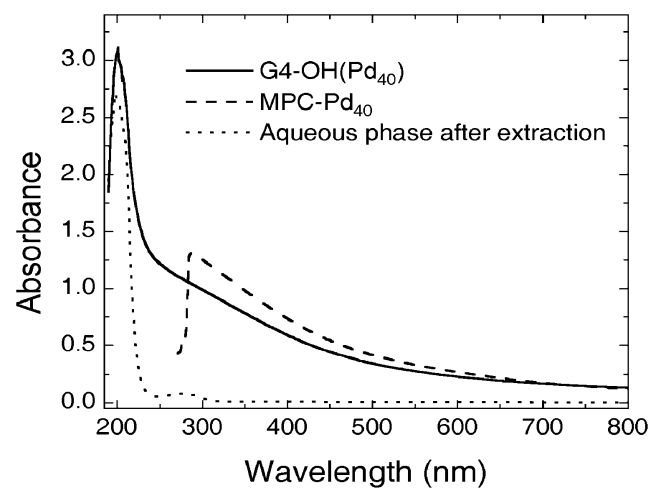

Figure 1. UV-vis absorbance spectra demonstrating extraction of Pd nanoparticles from a $6.25 \mu \mathrm{M}$ G4- $\mathrm{OH}\left(\mathrm{Pd}_{40}\right)$ solution. The solid line corresponds to the aqueous phase before extraction, the dashed line was obtained from the toluene phase after extraction, and the dotted line corresponds to the aqueous phase after extraction. In all cases the concentration of Pd atoms is $250 \mu \mathrm{M}$.
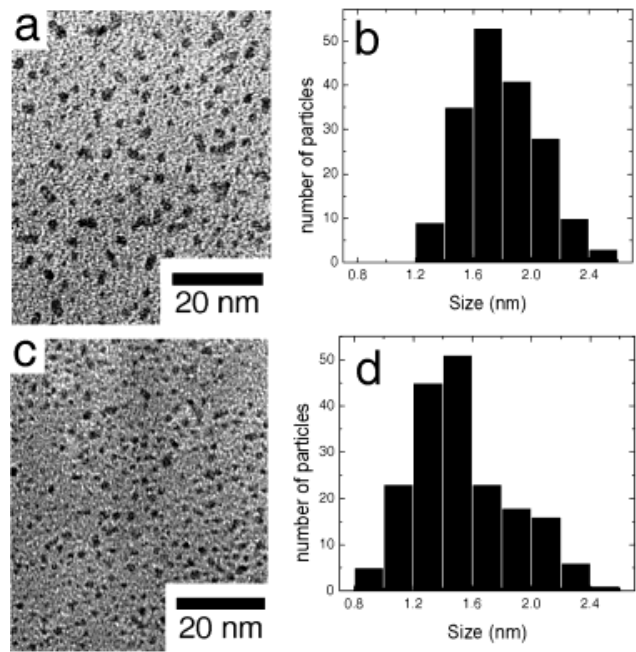

Figure 2. HRTEM micrographs and size-distribution histograms for (a, b) $\mathrm{G} 4-\mathrm{OH}\left(\mathrm{Pd}_{40}\right)$ and (c, d) $\mathrm{Pd}_{40}$ MPCs $\left(\mathrm{MPC}-\mathrm{Pd}_{40}\right)$ after extraction.

These results suggest that $n$-alkanethiols enter the dendrimer, adsorb to the surface of individual nanoparticles, extract them from the dendrimer, and transport them to the toluene phase (Scheme 1). This model is further supported by high-resolution transmission electron microscopy (HRTEM) images of the 40-atom Pd nanoparticles before $\left(\mathrm{G} 4-\mathrm{OH}\left(\mathrm{Pd}_{40}\right)\right)$ and after $\left(\mathrm{MPC}-\mathrm{Pd}_{40}\right)$ extraction (Figure 2). Before extraction, the Pd DENs have an average metalcore diameter of $1.7 \pm 0.4 \mathrm{~nm}$, which is in accord with our previous results for similarly prepared materials. ${ }^{6,7}$ After extraction the particle size is $1.5 \pm 0.3 \mathrm{~nm}$. Note that 40 -atom Pd nanoparticles should have a diameter of about $1.1 \mathrm{~nm} .{ }^{6}$ At present, we do not understand why the TEM data indicate the particles are so large, but this is a highly reproducible result. ${ }^{6,7}$ The data strongly suggest that individual nanoparticles are extracted from the dendrimer without significant loss of metal or aggregation. We have obtained similar results, which will be reported separately, for Au nanoparticles. Dendrimers containing 55-atom Au nanoparticles were found to have an average particle size of $1.3 \pm 0.3 \mathrm{~nm}$ before extraction, while after extraction the resulting Au MPCs have an average size of $1.5 \pm 0.4 \mathrm{~nm}$.

To summarize, we have shown that Pd nanoparticles can be extracted from dendrimers into toluene in the form of $n$-alkanethiolstabilized MPCs. Within the accuracy of absorbance spectroscopy, the extraction yield is quantitative. Moreover, TEM data indicate that the Pd nanoparticles are nearly size monodisperse and that within the resolution of HRTEM their average size is the same before and after extraction. This synthetic approach is simple, provides highly reproducible results, eliminates the need for purification, and should be broadly applicable for controlling the size and composition of MPCs. The synthesis and characterization of $\mathrm{Au}$ and bimetallic MPCs prepared using this approach will soon be reported. Experiments are also planned to better understand how the nanoparticle transfers through the dense dendrimer periphery.

Acknowledgment. We gratefully acknowledge the American Chemical Society Petroleum Research Fund (Grant No. 35756AC5,7) and the National Science Foundation (Grant No. 0211068) for financial support. We thank Dr. Julio C. Alvarez and Orla M. Wilson for helpful discussions.

Supporting Information Available: Photographs showing the extraction of Pd nanoparticles from the aqueous to the toluene phase, comparison of UV-vis absorbance spectra of a G4-OH solution and the aqueous phase after extraction, FT-IR spectra of the aqueous and toluene phases after extraction, and NMR data demonstrating that $n$-alkanethiols stabilize the Pd nanoparticles after extraction (PDF). This material is available free of charge via the Internet at http://pubs.acs.org.

\section{References}

(1) Whetten, R. L.; Shafigullin, M. N.; Khoury, J. T.; Schaaff, T. G.; Vezmar, I.; Alvarez, M. M.; Wilkinson, A. Acc. Chem. Res. 1999, 32, 397-406.

(2) Templeton, A. C.; Wuelfing, W. P.; Murray, R. W. Acc. Chem. Res. 2000 $33,27-36$.

(3) Brust, M.; Kiely, C. J. Colloids Surf. A 2002, 202, 175-186.

(4) Crooks, R. M.; Zhao, M.; Sun, L.; Chechik, V.; Yeung, L. K. Acc. Chem Res. 2001, 34, 181-190.

(5) Zhao, M.; Sun, L.; Crooks, R. M. J. Am. Chem. Soc. 1998, 120, 48774878 .

(6) Zhao, M.; Crooks, R. M. Angew. Chem., Int. Ed. 1999, 38, 364-366

(7) Niu, Y.; Yeung, L. K.; Crooks, R. M. J. Am. Chem. Soc. 2001, 123, 68406846.

(8) Li, Y.; El-Sayed, M. A. J. Phys. Chem. B 2001, 105, 8938-8943.

(9) Zheng, J.; Petty, J. T.; Dickson, R. M. J. Am. Chem. Soc. 2003, 125 $7780-7781$

(10) Esumi, K.; Satoh, K.; Torigoe, K. Langmuir 2001, 17, 6860-6864.

(11) Michels, J. J.; Huskens, J.; Reinhoudt, D. N. J. Chem. Soc., Perkin Trans. 2 2002, 102-105.

(12) Brust, M.; Walker, M.; Bethell, D.; Schiffrin, D. J.; Whyman, R. J. Chem. Soc., Chem. Commun. 1994, 801-802.

(13) Carotenuto, G.; Nicolais, L. Mater. Chem. 2003, 13, 1038-1041.

(14) Hostetler, M. J.; Wingate, J. E.; Zhong, C.-Z.; Harris, J. E.; Vachet, R. W.; Clark, M. R.; Londono, J. D.; Green, S. J.; Stokes, J. J.; Wignall, G. D.; Glish, G. L.; Porter, M. D.; Evans, N. D.; Murray, R. W. Langmuir 1998, 14, 17-30.

(15) Chen, S.; Huang, K.; Stearns, J. A. Chem. Mater. 2000, 12, 540-547.

(16) Yee, C. K.; Jordan, R.; Ulman, A.; White, H.; King, A.; Rafailovich, M. Sokolov, J. Langmuir 1999, 15, 3486-3491.

(17) Cliffel, D. E.; Zamborini, F. P.; Gross, S. M.; Murray, R. W. Langmuir 2000, 16, 9699-9702.

(18) Zamborini, F. P.; Gross, S. M.; Murray, R. W. Langmuir 2001, 17, 481488.

(19) Templeton, A. C.; Pietron, J. J.; Murray, R. W.; Mulvaney, P. J. Phys. Chem. B 2000, 104, 564-570.

(20) Chechik, V.; Zhao, M.; Crooks, R. M. J. Am. Chem. Soc. 1999, 121, 4910-4911.

JA037196Y 